
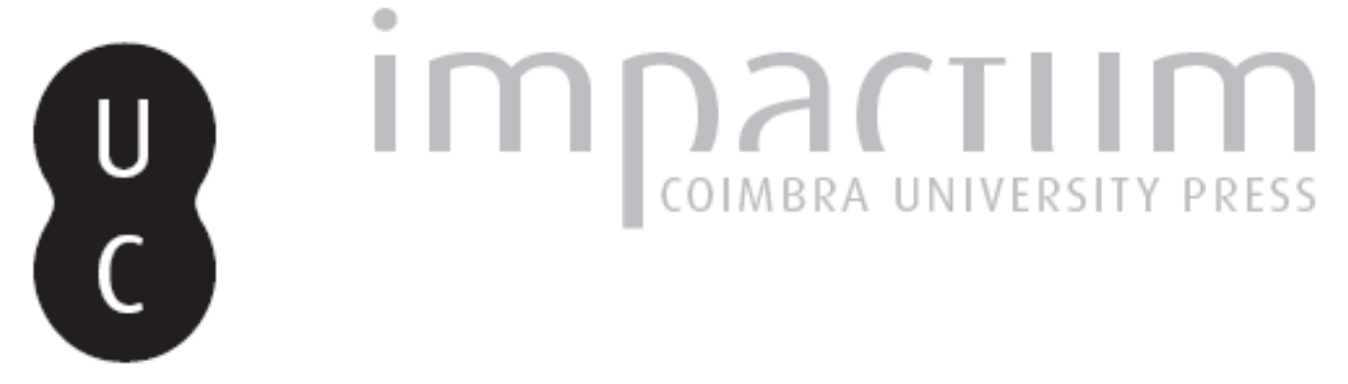

\title{
Riscos de avanço do mar e outros riscos num pequeno livro de apoio turístico
}

Autor(es): Rebelo, Fernando

Publicado por: Associação Portuguesa de Riscos, Prevenção e Segurança

URL persistente:

URI:http://hdl.handle.net/10316.2/40126

DOI:

DOI:https://doi.org/10.14195/1647-7723_6_8

Accessed : $\quad$ 26-Apr-2023 10:52:09

A navegação consulta e descarregamento dos títulos inseridos nas Bibliotecas Digitais UC Digitalis, UC Pombalina e UC Impactum, pressupõem a aceitação plena e sem reservas dos Termos e Condições de Uso destas Bibliotecas Digitais, disponíveis em https://digitalis.uc.pt/pt-pt/termos.

Conforme exposto nos referidos Termos e Condições de Uso, o descarregamento de títulos de acesso restrito requer uma licença válida de autorização devendo o utilizador aceder ao(s) documento(s) a partir de um endereço de IP da instituição detentora da supramencionada licença.

Ao utilizador é apenas permitido o descarregamento para uso pessoal, pelo que o emprego do(s) título(s) descarregado(s) para outro fim, designadamente comercial, carece de autorização do respetivo autor ou editor da obra.

Na medida em que todas as obras da UC Digitalis se encontram protegidas pelo Código do Direito de Autor e Direitos Conexos e demais legislação aplicável, toda a cópia, parcial ou total, deste documento, nos casos em que é legalmente admitida, deverá conter ou fazer-se acompanhar por este aviso.

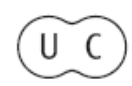




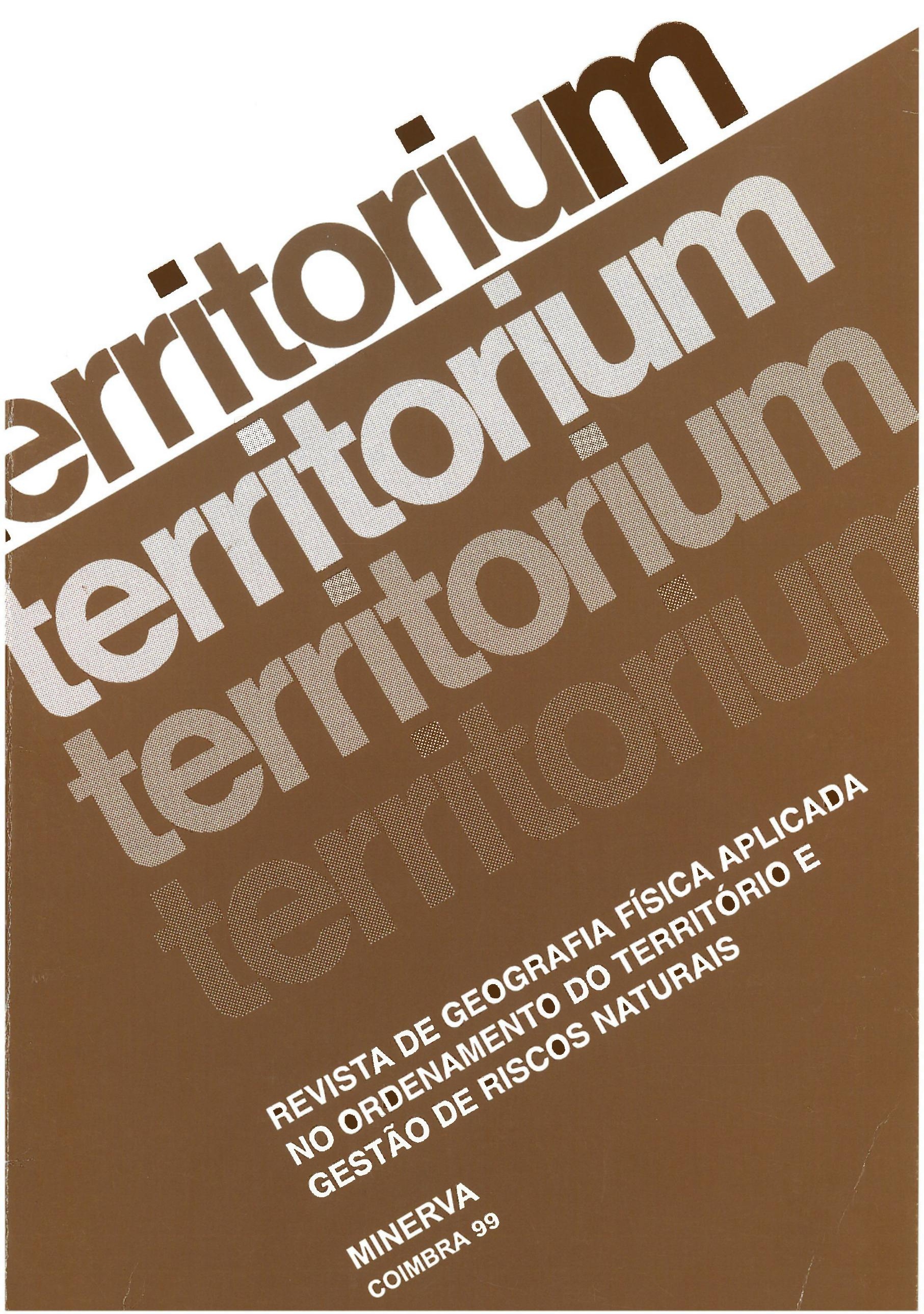


cações foram transformadas em artigos que sãopublicados no presente número.

$\mathrm{O}$ programa do $\mathrm{V}$ Encontro continuou com a apresentação de um vídeo sobre a Geografia Física (comparada) das Ilhas de S. Miguel e da Madeira da autoria de Raimundo Quintal, geógrafo e vereador da Câmara Municipal do Funchal, que, logo a seguir, fez uma intervenção sobre as inundações catastróficas ("aluviões") da Madeira, trabalho igualmente publicado neste número. O caso dramático dos desabamentos mortíferos da Ribeira Quente (S. Miguel, Açores), apresentado em nota breve no número 5 da Territorium, foi tratado por António Guilherme Raposo, geógrafo e técnico da Direcção Regional do Ambiente dos Açores. Finalmente, o Prof. Doutor Ivo Alves, do Departamento de Ciências da Terra da Faculdade de Ciências e Tecnologia da Universidade de Coimbra, apresentou o seu método de determinação de sismos.

\section{Riscos de avanço do mar e outros riscos num pequeno livro de apoio turístico}

\section{Fernando Rebelo}

José Nunes André e Maria de Fátima Neves Cordeiro publicaram, em edição da Câmara Municipal de Leiria e com data de 1999, um pequeno livro intitulado Percurso ambiental-geobotânico da Lagoa da Ervedeira a S. Pedro de Moel (Matas Nacionais do Pedrógão e de Leiria). Com um total de 64 páginas, muito ilustrado com fotografias e mapas, este livro de apoio a um turismo de cariz ambiental tão na moda, depois de uma nota introdutória, muito rápida, dá o enquadramento geográfico e geológico da área em causa e um enquadramento florestal, com um pouco de história que permite desde logo entender como surgiram, se desenvolverame foram sobrevivendo aquelas Matas Nacionais.

A partir da página 23, os Autores fazem a descrição das paragens e dos locais de observação que acharam merecerem referência específica. Pela Lagoa da Ervedeira inicia-se, pois, um interessante e educativo passeio, que logo continua pela Praia de Pedrógão onde o problema do avanço do mar já é quantificado ("0,9 m/anode 1991 a 1997"), segundo uma estimativa de P. CUNHA et al. (1997). Segue-se a viagem para Sul e novos dados sobre o avanço do mar aparecem, agora baseados em trabalho de J. N. ANDRÉ (1996) _ "2,2 m/ano de 1979 a 1991"; mas também são apresentados valores para o avanço dunar - "de 1991 a 1995 a progressão das areias eólicas em direcção à ETAR (...) foi de cerca de $25 \mathrm{~m} / \mathrm{ano}$, soterrando e crestando pinheiros achaparrados com cerca de $2 \mathrm{~m}$ de altura" (p. 29).

Tambémas fotografias aéreas ajudam a acompanhar o texto seja quando se fala de dunas e se mostram os riscos do pisoteio antrópico, seja quando se fala da construção de molhes e se mostram manifestações de riscos em áreas de avanço do mar favorecido por essa construção.

Referências a árvores classificadas como "notáveis" devidamente documentadas por fotografias, tal como a paisagens de grande beleza, alternam com informações sobre dunas conservadas ou em destruição pelo homem. Por vezes, não se explicam os riscos, mas o leitor atento apercebe-se deles.

Estão de parabéns os Autores por terem tratado o tema de maneira tão didáctica e estão de parabéns a Câmara Municipal de Leiria, porque editou, e a Câmara Municipal da Marinha Grande, porque apoiou a edição deste livro que para além de mostrar os mais belos pontos turísticos da região, também dá elementos de ordem científica para a sua compreensãoe, através de uma boa bibliografia, oferece pistas para estudos mais aprofundados.

\section{REFERÊNCIAS BIBLIOGRÁFICAS}

ANDRÉ, José Nunes (1996) - Morfologia litoral da área compreendida entre o Cabo Mondego e S. Pedro de Moel. Dissertação de Mestrado apresentada à Faculdade de Letras da Universidade de Coimbra. 164 p. pol.

ANDRÉ, José Nunes (1996) - "Breve nota sobre o recuo da linha de costa e a intervenção humana a sul da Figueira da Foz". Territorium, 3, p. 57-58.

CUNHA, P. Proença, SILVA, A. Freire da, ANDRÉ, J. Nunes e CABRAL, M. Cristina (1997) - "Considerações sobre a evolução actual do litoral entre a Figueira da Foz e a Nazaré". Colectânea de ideias sobre a Zona Costeira de Portugal, Porto, Associação Eurocoast-Portugal, p. 503-524. 